\title{
The Role of Sonoelastography in Diagnosis and Grading of Patients with Carpal Tunnel Syndrome
}

\author{
MENNATALLAH ELSAYED, M.D.*; MAHMOUD A. SABER MOHAMED, M.Sc.*; \\ LAMIA M. AFIFI, M.D.** and AHMED M. WAFAIE, M.D.*
}

The Departments of Radiodiagnosis* and Neurophysiology**, Faculty of Medicine, Cairo University

\begin{abstract}
Background: Carpal tunnel syndrome is a result of median nerve compression by its surrounding anatomical structures. Ultrasonographic examination of the carpal tunnel can give information regarding the anatomical abnormalities of the median nerve and carpal tunnel contents, which may result in carpal tunnel syndrome. Pathophysiology of carpal tunnel syndrome can be evaluated through assessment of the elasticity of the carpal tunnel contents using sonoelastography. The two major applications in sonoelastography are strain elastography and shearwave elastography.
\end{abstract}

Aim of Study: The purpose of this study was how to analyse the potential of the greyscale ultrasound, strain elastography and shearwave elastographing in diagnosing and grading carpal tunnel syndrome with the electrophysiological results used as the diagnostic reference.

Patients and Methods: Grey scale ultrasound and sonoelastography analysis of the participants of this study was done to 100 wrists; 50 wrists ( 7 males and 43 females) regarded as cases and 50 normal wrists ( 38 males and 12 females) regarded as controls. Age range for cases was 24 to 75 years (mean of 46.32 $\pm 14.29 \mathrm{SD}$ ). Age range for control group was 17 to 56 years (mean of $35.04 \pm 11.64 \mathrm{SD}$ ). Data was presented using mean and standard deviation for quantitative variables and frequency and percentage for qualitative ones. Comparison between groups for quantitative variables was performed using Independent sample test (if 2 groups) or One-way ANOVA with post-hoc Tukey's test for pairwise comparisons (if $>2$ groups). Association of ordinal and quantitative variables was performed through Spearman correlation coefficients. Receiver Operating Characteristics (ROC) curve analysis was conducted to explore the discriminant abilities of different nerve conduction measures to differentiate Carpal tunnel syndrome patients from controls, in addition to selection of the most appropriate cut-off points using the Youden Index (J). $p$-values less than or equal to 0.05 were considered statistically significant.

Results: Sonoelastography parameters were able to diagnose carpal tunnel syndrome with variably high accuracy, with strain ratio and Shearwave elastography being the most accurate of the investigated parameters. We suggested cut off

Correspondence to: Dr. Mennatallah Elsayed, The Department of Radiodiagnosis, Faculty of Medicine, Cairo University values of 1.26 and $46.95 \mathrm{kPa}$ for strain ratio and Shearwave elastography respectively for the diagnosis of carpal tunnel syndrome. The forementioned cut off values produced $100 \%$, $98 \%$ sensitivities and $100 \%, 98 \%$ specificities for strain ratio and Shearwave elastography respectively. As for grading, cut off values for the examined parameters that accurately represents the different grades of disease severity could not be established.

Conclusion: Grey scale ultrasound and sonoelastography provided significant improvement in the diagnostic accuracy in the assessment of carpal tunnel syndrome. As for grading of the severity of carpal tunnel syndrome, we recommend the implementation of further studies with larger sample volume to yield better results.

Key Words: Carpal tunnel syndrome - Grey scale ultrasound - Sonoelatography.

\section{Introduction}

CARPAL tunnel syndrome is a very usual condition, in which there is neuropathy of median nerve due to compression at wrist level. The patient usually presents with rather specific symptoms, including tingling and numbness in the median nerve distribution territory and weakness in thumb opposition [1]. Carpal tunnel syndrome is a result of median nerve compression by its surrounding anatomical structures, including the transverse carpal ligament, finger flexor tendons, and tenosynovial tissue [2].

It was previously stated in the literature that ultrasonographic examination of the carpal tunnel can give information regarding the anatomical abnormalities of the median nerve and carpal tunnel contents, which may result in carpal tunnel syndrome [3]. Many studies have demonstrated the pathophysiology of carpal tunnel syndrome through evaluation of the elasticity of the carpal tunnel contents using sonoelastography [4]. The two major applications in sonoelastography are strain elastography and shearwave elastography. Strain elastog- 
raphy, also named as static strain elastography, is based on the principle that tissue compression produces strain [5]. In share wave elastography, Shear waves are generated using focused acoustic radiation force from a linear US array, which by itself provides a local stress and generates local displacement in the tissue [6].

Aim of work: In this study, we were focusing on how to employ the greyscale ultrasound and sonoelastography in diagnosing and grading carpal tunnel syndrome. Data was presented using mean and standard deviation for quantitative variables and frequency and percentage for qualitative ones. Comparison between groups for quantitative variables was performed using Independent sample test (if 2 groups) or One-way ANOVA with posthoc Tukey's test for pairwise comparisons (if $>2$ groups). Association of ordinal and quantitative variables was performed through Spearman correlation coefficients. Receiver Operating Characteristics (ROC) curve analysis was conducted to explore the discriminant abilities of different nerve conduction measures to differentiate Carpal tunnel syndrome patients from controls, in addition to selection of the most appropriate cut-off points using the Youden Index $(\mathrm{J}) . p$-values less than or equal to 0.05 were considered statistically significant.

\section{Patients and Methods}

\section{Patients:}

In this case control prospective study, we performed ultrasound study for 100 subjects referred to the Radiology Departments of Cairo University Hospitals from the Department of Neurophysiology Department. 50 wrists clinically diagnosed to have carpal tunnel syndrome, confirmed by electrophysiological test were regarded as cases. The other 50 wrists of healthy volunteers were considered as controls. As regards the age distribution, the participants ranged from 17 years old up to 75 years old with the most commonly occurring age group being around 20 to 49 years old. Forty-five percent of the participants were males and fifty-five percent were females. The examined wrists were $49 \%$ left side and $51 \%$ right side.

The study took place in the period of September 2019 to December 2020. This study has been approved by the ethical committee and the reviewers board of Cairo University's Faculty of Medicine. An informed oral consent was gathered from every participant.

\section{Inclusion criteria:}

Patients diagnosed (both clinical and electrophysiology) with carpal tunnel syndrome.

\section{Exclusion criteria:}

None of the patients were excluded based on our exclusion criteria which were detailed as follows:

Any patient with history of wrist trauma, previous surgery for carpal tunnel syndrome or neuropathies due to diabetes mellitus, hyperthyroidism, chronic renal failure, cervical radiculopathy, polyneuropathy and previous injection with corticosteroid.

\section{Methods:}

We recorded the following data:

1- The electrophysiology diagnosis as well as the electrophysiology grade (mild, moderate, or severe carpal tunnel syndrome).

2- B-mode assessment of the median nerve through:

a-Perimeter of the median nerve: It was recorded through visualizing the median nerve at the level of the carpal tunnel in transverse section. Following this step, free hand selection of the median nerve outline in the B-mode image was done and the machine calculated the measurement in millimeters.

$b$-Circumferential surface area of the median nerve: It was recorded by visualization the median nerve at the level of the carpal tunnel (the bony landmark was the pisiform bone) in transverse section then the operator used free hand selection tool to follow the surface of the nerve. Lastly, the machine calculated the surface area in square millimeters.

\section{3- Elastography parameters:}

a-Shearwave elastography: The median nerve is scanned at the level of the carpal tunnel in longitudinal section then a region of interest is placed overlying the full thickness of the nerve and a measurement was produced by the machine in $\mathrm{kPa}$.

$b$ - Strain of the median nerve: The median nerve was scanned at the level of the carpal tunnel in longitudinal section. Then after selecting the strain function in the machine, repetitive equal compressions by the probe on the skin surface are applied until the machine generates an acceptable curve sufficient for recording the measurement.

$c$ - Strain ratio of the median nerve: A segment of the median nerve was visualized at the level of the lower forearm and wrist in longitudinal section. 
Then measurements of the median nerve strain at both the level of the carpal tunnel and proximal to the carpal tunnel were recorded after selecting the function of strain ratio in the machine.

The machine used was: Toshiba Aplio 500 with multifrequency linear array transducer.

\section{Patient positioning: (Fig. 1)}

All ultrasound examinations were performed while the subjects were seated facing the examiner. The arms were extended; the forearm was in the supine position and the wrists resting on a flat surface. Care was taken to examine in a neutral position and avoid any wrist and hand position that increased the carpal tunnel pressure. The fingers were held in a relaxed position while they were semi flexed. The patients were instructed not to move their wrists or fingers during the whole sonographic examination.

\section{Data analysis:}

- The electrophysiological results was used as the diagnostic reference for diagnosing and grading of the carpal tunnel syndrome.

- The sonographic and elastographic values of median nerve were correlated with the electrophysiological test results to provide both diagnostic value and grading values for carpal tunnel syndrome.

- The grading values were correlated with electrophysiological tests and categorized into (mild, moderate and severe).

\section{Statistical analysis:}

Data was entered and statistically analyzed on the Statistical Package of Social Science Software program, version 25 (IBM SPSS Statistics for Windows, Version 25.0. Armonk, NY: IBM Corp.). Data was presented using mean and standard deviation for quantitative variables and frequency and percentage for qualitative ones. Comparison between groups for quantitative variables was performed using Independent sample test (if 2 groups) or One-way ANOVA with post-hoc Tukey's test for pairwise comparisons (if $>2$ groups). Association of ordinal and quantitative variables was performed through Spearman correlation coefficients. Receiver Operating Characteristics (ROC) curve analysis was conducting to explore the discriminant abilities of different nerve conduction measures to differentiate Carpal tunnel syndrome patients form controls, in addition to selection of the most appropriate cut-off points using the Youden Index $(\mathrm{J}) . p$-values less than or equal to 0.05 were considered statistically significant.

\section{Results}

The details of the sample distribution according to age, sex, and laterality between the cases and control groups are shown in Table (1).

Regarding the electrophysiology findings of the cases group, the moderate form of the disease was the commonest form among the patients accounting for $44 \%$ of the examined wrists. The wrists diagnosed with severe form of carpal tunnel syndrome were the least commonly occurring group accounting for fifth of the cases. A mild degree of carpal tunnel syndrome was found in about third of the diseased wrists. The The exact numbers and percentages are displayed in Table (2).

We examined and categorized the median nerve conductivity of the cases and control according to five ultra-sonography and elastography parameters. These parameters were B-mode assessment of the median nerve perimeter measured in millimeters; B-mode assessment of the circumferential surface area of the median nerve measured in square millimeter; elastography assessment of the median nerve through measuring its strain at the level of the carpal tunnel, the strain ratio of the median nerve, as well as the shearwave analysis of the median nerve (which was measured in $\mathrm{kPa}$ ). The detailed mean measurements of the five postulated conduction parameters across the cases and control groups are illustrated in Figs. $(2,3)$ with comparison between their values.

Each of the five postulated ultrasound and elastography nerve conduction parameters was tested for its sensitivity and specificity to detect their diagnostic power with the electrophysiology regarded as the gold standard. A postulated cutoff value for each parameter was reached through ROC curve analysis of the given measurements. These cut-off values as well as the diagnostic performance figures of said cut-off values are presented in Table (3). Fig. (4) shows the ROC curves of the five parameters.

The comparison of nerve conduction parameters regarding the electrophysiological grade:

Sub-group analysis of the cases group was done to correlate the electrophysiological degree of carpal tunnel syndrome severity to the five postulated ultra-sonography and elastography parameters investigated in our study. A mean value (with standard deviation) for each electrophysiological grade of CTS severity (mild, moderate, severe) was calculated. These values are presented in Table (4). 
Table (1): Age, sex, and laterality distribution of the sample.

\begin{tabular}{llll}
\hline Group & $\begin{array}{l}\text { Case } \\
(\mathrm{n}=50)\end{array}$ & $\begin{array}{l}\text { Control } \\
(\mathrm{n}=50)\end{array}$ & $p$-value \\
\hline Age (years): & & & \\
$\quad$ Range & $24-75$ & $17-56$ & $\mathbf{0 . 0 0 0}$ \\
$\quad$ Mean \pm SD & $46.32 \pm 14.29$ & $35.04 \pm 11.64$ & \\
$\begin{array}{l}\text { Gender: } \\
\quad \text { Male }\end{array}$ & $7(14 \%)$ & $38(76 \%)$ & $\mathbf{0 . 0 0 0}$ \\
$\quad$ Female & $43(86 \%)$ & $12(24 \%)$ & \\
Side: & & & \\
$\quad$ Right & $26(52 \%)$ & $25(50 \%)$ & 0.841 \\
$\quad$ Left & $24(48 \%)$ & $25(50 \%)$ & \\
\hline
\end{tabular}

Table (2): Number of cases based on electrophysiology grade.

\begin{tabular}{cc}
\hline Electrophysiological grade of cases & Number of wrists (\%) \\
\hline Mild & $18(36 \%)$ \\
Moderate & $22(44 \%)$ \\
Severe & $10(20 \%)$ \\
\hline
\end{tabular}

Table (3): Diagnostic performance and cut off values of study parameters.

\begin{tabular}{|c|c|c|c|c|}
\hline & $\begin{array}{c}\text { AUC } \\
(95 \% \mathrm{CI})\end{array}$ & $\begin{array}{l}\text { Cut- } \\
\text { off }\end{array}$ & $\begin{array}{l}\text { Sensi- } \\
\text { tivity }\end{array}$ & $\begin{array}{l}\text { Speci- } \\
\text { ficity }\end{array}$ \\
\hline $\begin{array}{l}\text { Median nerve } \\
\text { perimeter }\end{array}$ & $\begin{array}{l}0.983 \\
(0.963-1)\end{array}$ & $\geq 13.10$ & $96.0 \%$ & $92.0 \%$ \\
\hline Median nerve CSA & $\begin{array}{l}0.886 \\
(0.822-0.95)\end{array}$ & $\geq 8.85$ & $86.0 \%$ & $72.0 \%$ \\
\hline $\begin{array}{l}\text { Strain of median nerve } \\
\text { at carpal tunnel }\end{array}$ & $\begin{array}{l}0.909 \\
(0.845-0.973)\end{array}$ & $\leq 0.14$ & $92.0 \%$ & $82.0 \%$ \\
\hline Strain ratio & $\begin{array}{l}1 \\
(1-1)\end{array}$ & $\geq 1.26$ & $100.0 \%$ & $100.0 \%$ \\
\hline $\begin{array}{l}\text { Shear wave at wrist } \\
\text { (Kpa) }\end{array}$ & $\begin{array}{l}0.992 \\
(0.98-1)\end{array}$ & $\geq 46.95$ & $98.0 \%$ & $98.0 \%$ \\
\hline
\end{tabular}

Table (4): Correlation between the study parameters and grade of CTS.

\begin{tabular}{lllll}
\hline & \multicolumn{3}{c}{ Electrophysiological grade } & $\begin{array}{c}p \text { - } \\
\text { value }\end{array}$ \\
\cline { 2 - 4 } & Mild & Moderate & Severe & \\
\hline $\begin{array}{c}\text { Median nerve } \\
\text { perimeter }\end{array}$ & $15.86 \pm$ & $18.14 \pm$ & $20.43 \pm$ & $\mathbf{0 . 0 0 5}$ \\
Median nerve & $10.31 \pm$ & $15.51 \pm$ & $20.24 \pm$ & $\mathbf{0 . 0 0 0}$ \\
CSA & 2.95 & 6.43 & 7.82 & \\
Strain of median & $0.11 \pm$ & $0.08 \pm$ & $0.07 \pm$ & $\mathbf{0 . 0 0 1}$ \\
nerve at carpal & 0.04 & 0.03 & 0.02 & \\
tunnel & $2.04 \pm$ & $2.79 \pm$ & $3.78 \pm$ & $\mathbf{0 . 0 0 0}$ \\
Strain ratio & 0.81 & 0.53 & 0.68 & \\
Shear wave & $58.35 \pm$ & $86.38 \pm$ & $116 \pm$ & $\mathbf{0 . 0 0 0}$ \\
at wrist (Kpa) & 10.92 & 22.02 & 19.16 & \\
\hline
\end{tabular}

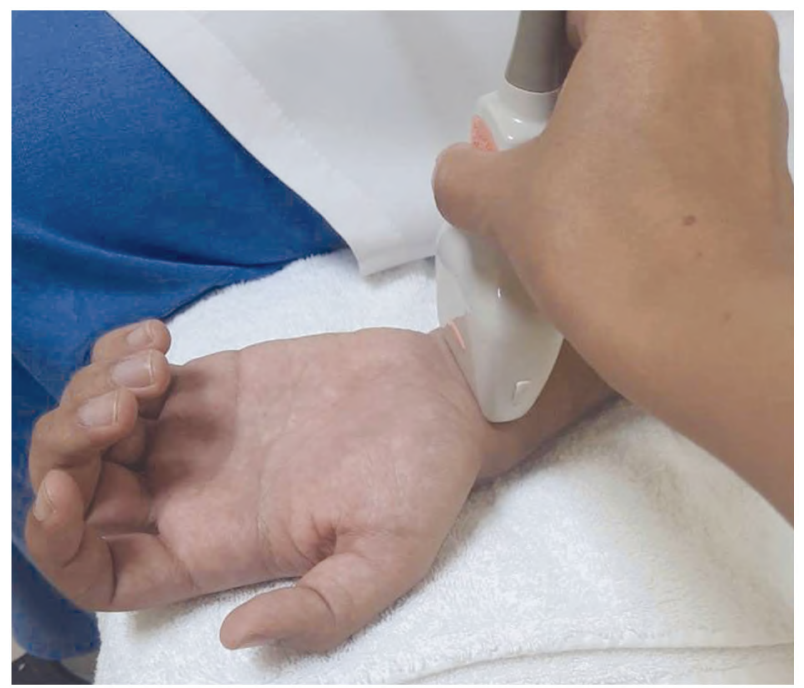

Fig. (1): Showing patient positioning during the exam.

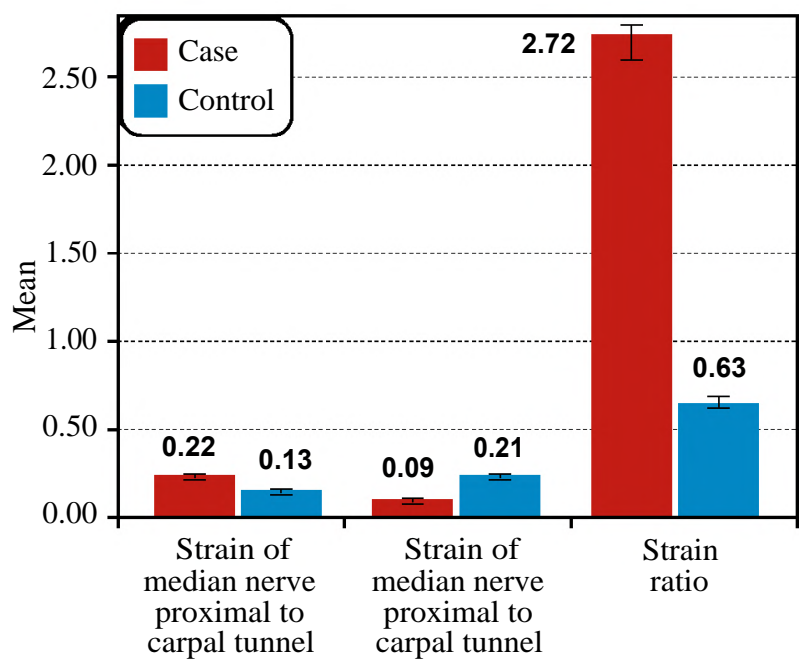

Fig. (2): Graph showing the differences in mean values between cases and controls.

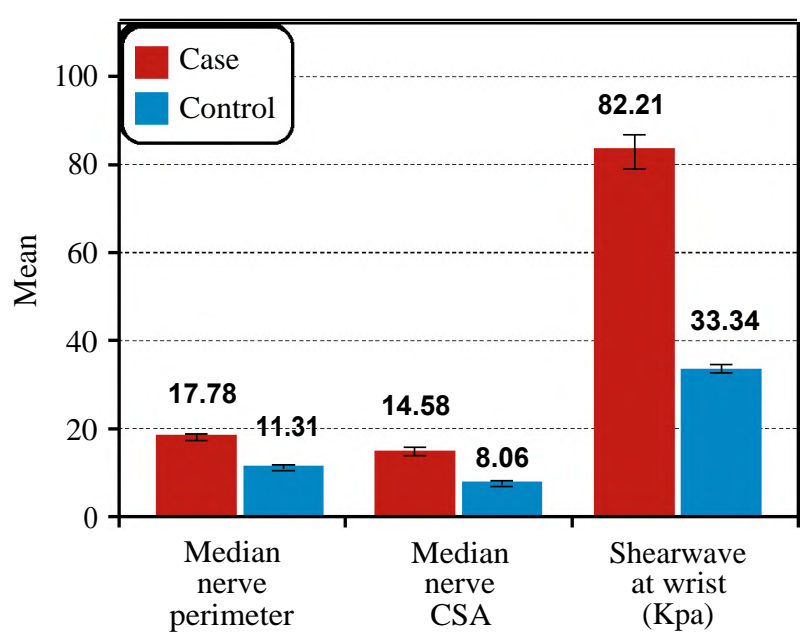

Fig. (3): Graph showing the differences in mean values between cases and controls. 


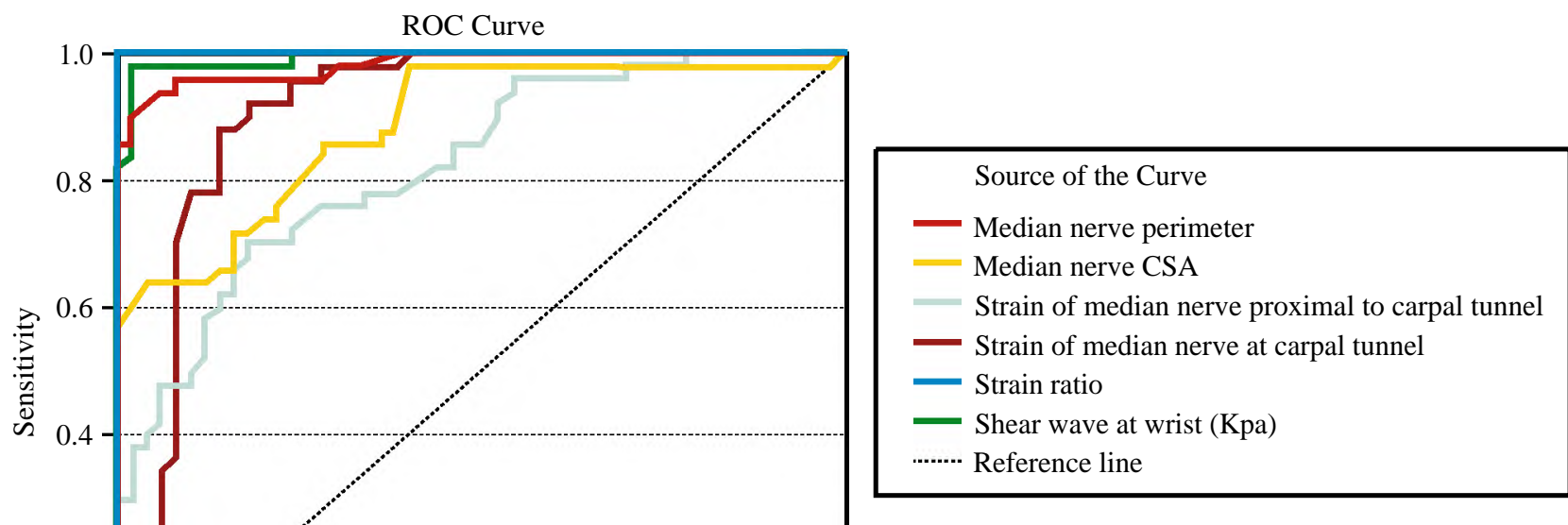

Fig. (4): Showing ROC curve analysis of the conduction parameters.
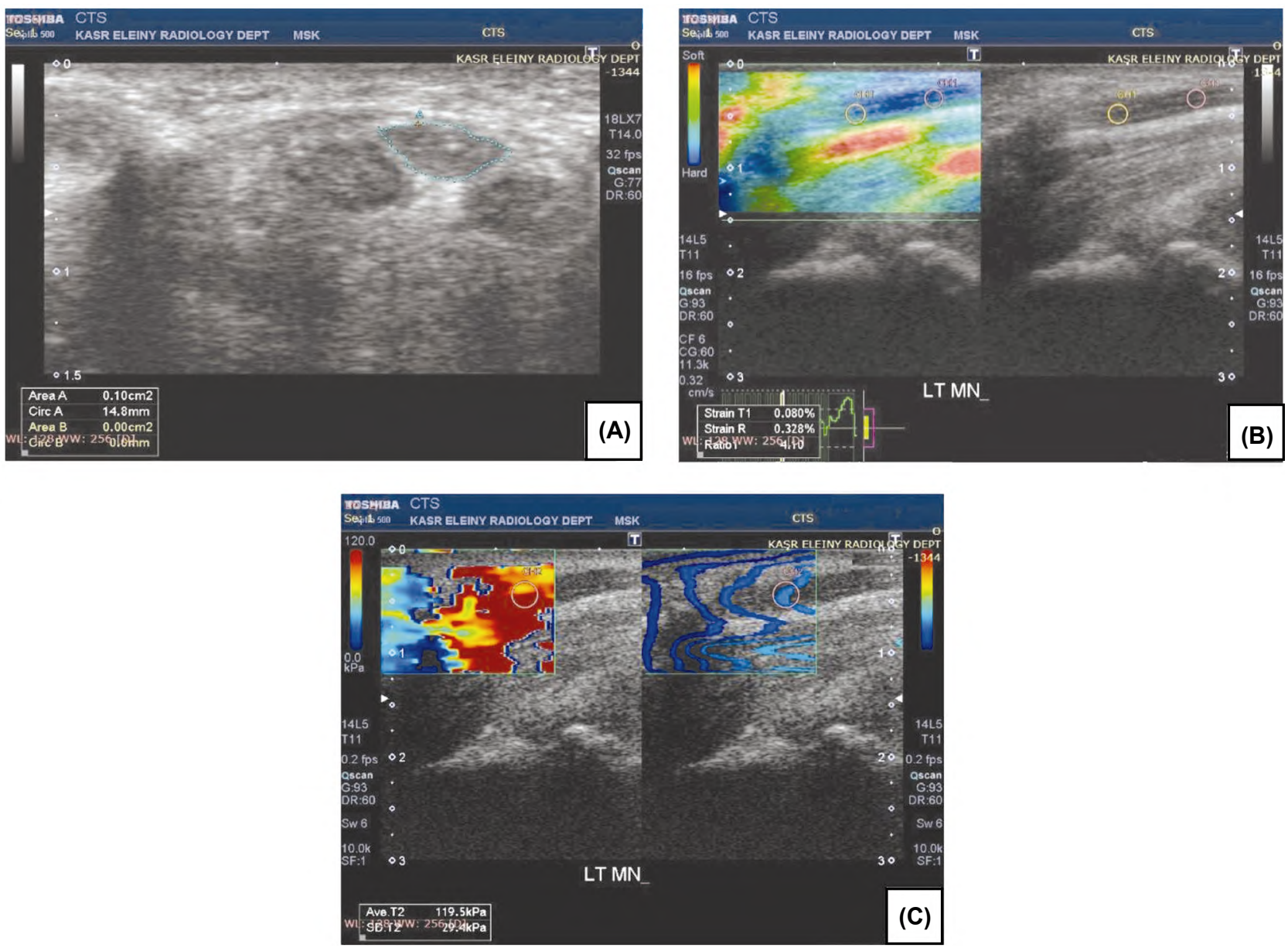

Fig. (5): A 75 year old male patient with severe entrapement of left median nerve at the level of wrist. (A) B mode assessment of median nerve revealed CSA of $0.10 \mathrm{~cm}^{2}$ (B) Strain Ratio 4.10 and strain value of 0.080 (C) Shearwave Elastography showed $119.5 \mathrm{kPa}$ 

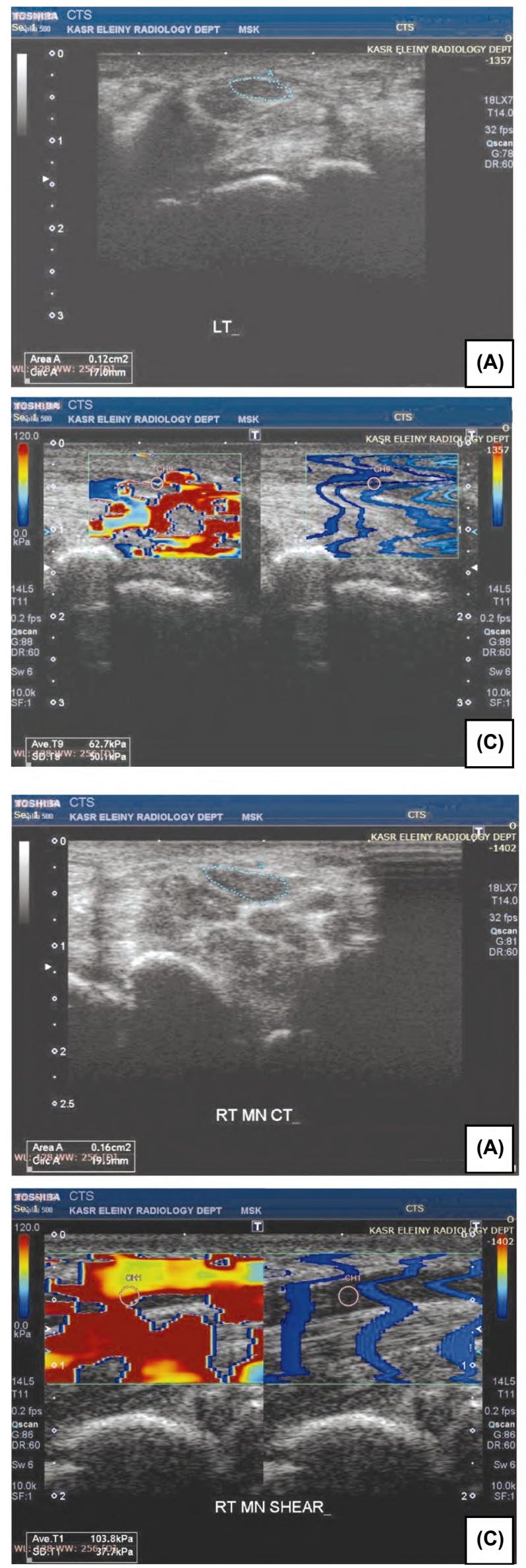

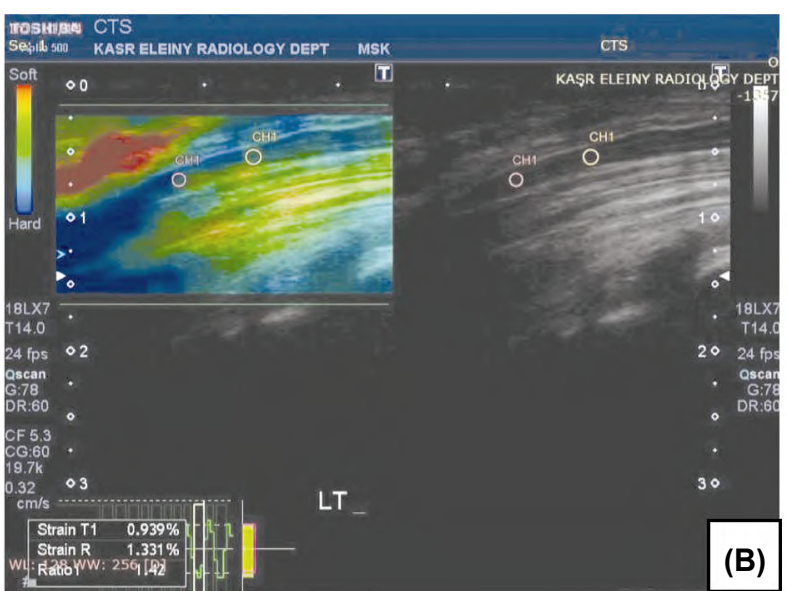

Fig. (6): A 60 year old female patient with moderate entrapment of the right median nerve at the level of wrist. (A) B mode assessment of median nerve revealed CSA of $0.16 \mathrm{~cm}^{2}$. (B) Strain Ratio showed 2.62 and strain value of 0.765. (C) Shearwave Elastography showed value of 103.8 $\mathrm{kPa}$.

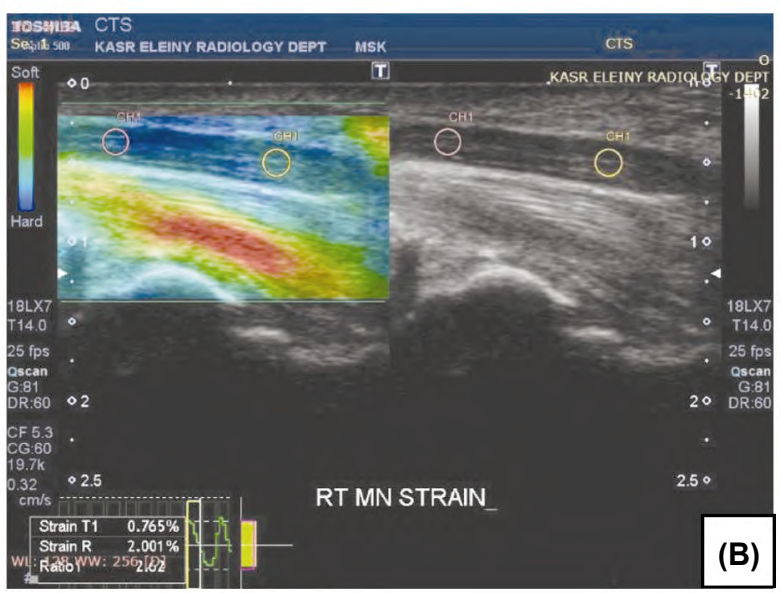

Fig. (7): A 27 year old female patient with mild entrapment of the both median nerves at the level of wrist. (A) B mode assessment of median nerve revealed CSA of 0.12 $\mathrm{cm}^{2}$. (B) Strain Ratio value of 1.42 , strain value of 0.939 . (C) Shearwave Elastography value of $62.7 \mathrm{kPa}$. 


\section{Discussion}

We evaluated 50 wrists diagnosed with carpal tunnel syndrome via a nerve conduction study by the means of several ultrasonography and elastography parameters. We then plotted the results of our assessment against 50 normal wrists. The imaging parameters used for our assessment were the median nerve perimeter, the median nerve surface area, the median nerve strain at level of the carpal tunnel, the median nerve strain ration, and the median nerve Shearwave elastography assessment. The diagnostic performance of each of the five parameters was assessed based on the sensitivity and specificity at differentiating cases from controls. Cut-off values for each parameter were determined based on ROC statistical analysis test. Figs. $(5,6,7)$ illustrate the sonoelastography of 3 cases with different grades of carpal tunnel syndrome.

In our evaluation of the median nerve perimeter, the cases established to be carpal tunnel syndrome were found to have a noticeably higher median nerve perimeter than the controls. The mean measurement for the cases was significantly higher than that of the controls (being $17.8 \mathrm{~mm}$ for cases vs. 11.3 for controls). A proposed cut off value of $13.1 \mathrm{~mm}$ was able to yield $96 \%$ sensitivity and 92\% specificity for diagnosing cases with carpal tunnel syndrome. As for grading, we found that the mean median nerve perimeter for mild CTS was $15.9 \mathrm{~mm}$. A mean of $18.1 \mathrm{~mm}$ was indicative of moderate affection of the median nerve; and a mean of $20.4 \mathrm{~mm}$ correlated to severe carpal tunnel syndrome.

Orman G., et al., [7] demonstrated the ability of the median nerve perimeter to diagnose cases as demonstrated a significant difference between the mean perimeter of the cases and the controls groups with that of the cases being $15.26 \mathrm{~mm}$ and the controls being $12.08 \mathrm{~mm}$. Their method of assessing the nerve perimeter was in accordance to the methodology used in our assessment. They however, yielded a narrower range for grading the severity of carpal tunnel syndrome with $12.08 \mathrm{~mm}$ value as a mean for the mild cases, $15 \mathrm{~mm}$ value as a mean value for the moderate cases, and 15.86 $\mathrm{mm}$ value for severe cases.

Sarraf P., et al., [8] however, yielded $85 \%$ sensitivity and $77 \%$ specificity for a cutoff value of $14.4 \mathrm{~mm}$ using a different approach in their assessment. For grading mild $13 \mathrm{~mm}$, moderate $16 \mathrm{~mm}$ and severe $18 \mathrm{~mm}$.
When investigating the circumferential surface area of the median nerve, we found out that a mean value of $14.6 \mathrm{~mm}^{2}$ correlated to the cases group and a mean value of $8 \mathrm{~mm}^{2}$ correlated to the controls group. A mean value of $10.3 \mathrm{~mm}^{2}$ was consistent with mild CTS, while $15.5 \mathrm{~mm}^{2}$ and $20.2 \mathrm{~mm}^{2}$ were consistent with moderate and severe CTS respectively.

Orman G., et al., [7] demonstrated a significant difference between the mean CSA of the cases and the controls groups with that of the cases being $11.81 \mathrm{~mm}^{2}$ and the controls being $7.76 \mathrm{~mm}^{2}$. These authors however demonstrated limited ability of the CSA at grading the severity of the median nerve affection on the contrary to our findings. This can be explained by their limited pool of patients with severe form of carpal tunnel syndrome $(n=4)$ which may have impacted the accuracy of their results.

Sarraf P., et al., [8] produced similar results to ours with similar diagnostic performance showing significant difference between cases and controls as regards the CSA of the median nerve. A cut off value of $10.5 \mathrm{~mm}^{2}$ yielded $80 \%$ sensitivity and $76 \%$ specificity at diagnosis. Concerning the ability to grade CTS severity, they however concluded a limited ability of CSA to grade the severity of CTS with high accuracy.

Our analysis of the median nerve strain at the carpal tunnel revealed good diagnostic performance as regards the diagnosis of CTS with however limited ability to grade the severity. The mean strain value of the cases group was significantly lower than the controls.

Other authors explored the diagnostic and grading performance of the median nerve strain at the carpal tunnel with relatively comparative results. Yoshii Y., et al., [9] used a device manufactured to apply equal and synchronized compressions to the skin surface in their assessment of the median nerve stiffness. Their method aimed to ensure reliable and reproducible results to eliminate the operator dependent variations elicited by manual compressions.

The mean measurement of the median nerve strain ratio in our study was significantly higher in the cases group as compared to the controls group with no overlap in the ranges of the two groups. A cut off value of 1.26 was able to correctly differentiate all the cases and controls with no false positive or false negative results. In our assessment, the strain ratio was able to categorize the cases 
into mild, moderate, and severe CTS with some overlap in between the groups.

Similarly Emara D., et al., [10] showed that cases have significantly higher strain ratio than controls. Martin M., et al., [11] analyzed their sample subjects according to the patient's body mass index (BMI) which they found to heavily confuse the strain ratio values. They also found that blood pressure control was also a confusing factor regarding assessment of strain ratio measurement. Tatar I.G., et al., [12] investigated the strain ratio of the median nerve at two different locations; at the carpal tunnel inlet (as in our study) and additionally in the proximal forearm. Their analysis yielded that the assessment of the strain ratio at the carpal tunnel is more accurate at diagnosing cases with CTS than the assessment in the proximal forearm. A cut off value of 2.3 was proposed.

In our study, the shearwave analysis of the median nerve at carpal tunnel was significantly higher in cases compared to controls with noticeable difference between the means of the different grades of severity. A cut off value of $46.95 \mathrm{kPa}$ yielded a sensitivity of $98 \%$ and specificity of $98 \%$ making shearwave elastography the second best parameter in diagnosing CTS among the parameters investigated in our study (next to strain ratio). According to Kantraci F. et al., [13] who conducted a study on 37 patients with carpal tunnel syndrome, a cut off value of $40.4 \mathrm{kPa}$ revealed a sensitivity of $93.3 \%$ and specificity of $88.9 \%$. Cingoz M. et al., [14] who evaluated 77 wrists with carpal tunnel syndrome established a cutoff value of $38.25 \mathrm{kPa}$ that was able to effectively diagnose carpal tunnel syndrome with a $78.6 \%$ sensitivity and $62.5 \%$ specificity. Another study of Wee T.C., et al., [15] that involved 47 wrists with carpal tunnel syndrome established a cut off value of $84 \mathrm{kPa}$ which is higher than the previously reported. The author explained the significant difference in results by the older age of the patients included in the study. Some authors speculated recently that CTS in the elderly may be a separate entity. Moran L. et al., [16] who conducted a different study that included 105 wrists with different degrees of carpal tunnel syndrome, aimed to establish a cutoff point to discriminate patients with moderate and severe CTS from mild cases. A cut off value of $57 \mathrm{kPa}$ was able to distinguish moderate and severe cases of CTS from mild and normal cases with a sensitivity of $46.5 \%$, a specificity of $89.6 \%$ and with $100 \%$ specificity if combined with CSA and cut off value $14 \mathrm{~mm}^{2}$.

\section{Conclusion:}

The investigated sonoelastography parameters were able to diagnose CTS with variably high accuracy with strain ratio and Shearwave elastography being the most accurate of the investigated parameters. Increased strain ratio and Shearwave elastography values highly correlate to the diagnosis of CTS. We suggest cut off values of 1.26 and $46.95 \mathrm{kPa}$ for strain ratio and Shearwave elastography respectively for the diagnosis of CTS. When using electrophysiology as the gold standard, the aforementioned cut off values produced $100 \%$, $98 \%$ sensitivities and $100 \%, 98 \%$ specificities for strain ratio and Shearwave elastography respectively. As for grading, cut off values for the examined parameters that accurately represents the different grades of disease severity could not be established. We regard this to the rather small volume of the subgroups. We recommend further studies with larger sample volume of the severity subgroups in order to yield accurate data for investigating the grading ability of the sonoelastography parameters.

\section{Conflict of interests:}

The authors declare that they have no conflicts of interest.

\section{Acknowledgements:}

We thank all patients and their families involved in the study. We thank all the authors for their contributions.

\section{References}

1- KEITH M.W., MASEAR V., CHUNG K.C., MAUPIN K., ANDARY M., AMADIO P.C., et al.: American Academy of Orthopaedic Surgeons Clinical Practice Guideline on diagnosis of carpal tunnel syndrome. J. Bone Joint Surg. Am., Oct. 91 (10): 2478-2479, 2009.

2- ETTEMA A.M., AMADIO P.C., ZHAO C., WOLD L.E. and AN K.N.: A histological and immunohistochemical study of the subsynovial connective tissue in idiopathic carpal tunnel syndrome. J. Bone Joint Surg. Am., 86-A: 1458-1466, 2004.

3- NARANJO A., OJEDA S., MENDOZA D., FRANCISCO F., QUEVEDO J.C. and ERAUSQUIN C.: What is the diagnostic value of ultrasonography compared to physical evaluation in patients with idiopathic carpal tunnel syndrome? Clin. Exp. Rheumatol., 25: 853-859, 2007.

4- MIYAMOTO H., HALPERN E.J., KASTLUNGER M., GABL M., ARORA R., BELLMANN-WEILER R., et al.: Carpal tunnel syndrome: Diagnosis by means of median nerve elasticity improved diagnostic accuracy of US with sonoelastography. Radiology, Feb. 270 (2): 481-486, 2014.

5- MIYAMOTO H., MORIZAKI Y., KASHIYAMA T. and TANAKA S.: Grey-scale sonography and sonoelastography for diagnosing carpal tunnel syndrome. World J. Radiol., 8 (3): 281-287, 2016. 
6- TALJANOVIC M.S., GIMBER L.H., BECKER G.W., LATT L.D., KLAUSER A.S., MELVILLE D.M., et al.: Shear-wave elastography: Basic physics and musculoskeletal applications. Radiographics, 37 (3): 855-870, 2017.

7- ORMAN G., OZBEN S., HUSEYINOGLU N., DUYMUS M. and ORMAN K.G.: Ultrasound Elastographic evaluation in the diagnosis of carpal tunnel Syndrome: Initial findings. Ultrasound in Medicine \& Biology, 39 (7): 11841189, 2013.

8- SARRAF P., MALEK M., GHAJARZADEH M., MIRI S., PARHIZGAR E. and EMAMI-RAZAVI S.Z.: The best cutoff point for median nerve cross sectional area at the level of carpal tunnel inlet. Acta. Med. Iran., 52 (8): 613-618, 2014.

9- YOSHII Y., TUNG W. and ISHII T.: Measurement of median nerve strain and applied pressure for the diagnosis of carpal tunnel syndrome. Ultrasound in Medicine \& Biology, 43 (6): 1205-1209, 2017.

10- EMARA D.M., EL SHAFEI M.M. and NABY H.M.: Utility of ultrasound elastography in a cohort of patients with idiopathic carpal tunnel syndrome. The Egyptian Journal of Radiology and Nuclear Medicine, 49 (2): 408 414, 2018.

11- MARTIN M.J. and CARTWRIGHT M.S.: A Pilot Study of Strain Elastography in the Diagnosis of Carpal Tunnel Syndrome. J. Clin. Neurophysiol., 34 (2): 114-118, 2017.

12- TATAR I.G., KURT A., YAVASOGLU N. and HEKIMOGLU B.: Carpal tunnel syndrome: Elastosonographic strain ratio and cross-sectional area evaluation for the diagnosis and disease severity. Medical Ultrasonography, 18 (3): 305, 2016.

13- KANTARCI F., USTABASIOGLU F.E., DELIL S., OLGUN D.C., KORKMAZER B. and DIKICI A.S.: Median nerve stiffness measurement by shear wave elastography: a potential sonographic method in the diagnosis of carpal tunnel syndrome. Eur. Radiol., 24 (2): 434-440, 2014.

14-CINGOZ M., KANDEMIRLI S.G., ALIS D.C., SAMANCI C., KANDEMIRLI G.C. and ADATEPE N.U.: Evaluation of median nerve by shear wave elastography and diffusion tensor imaging in carpal tunnel syndrome. European Journal of Radiology, 101: 59-64, 2018.

15- WEE T.C. and SIMON N.G.: Shearwave elastography in the differentiation of carpal tunnel syndrome severity. PM\&R, 12 (11): 1134-1139, 2020.

16- MORAN L., ROYUELA A., VARGAS A.P., LOPEZ A., CEPEDA Y. and MARTINELLI G.: Carpal tunnel syndrome: Diagnostic usefulness of ultrasound measurement of the median nerve area and quantitative elastographic measurement of the median nerve stiffness. Journal of Ultrasound in Medicine, 39 (2): 331-339, 2019.

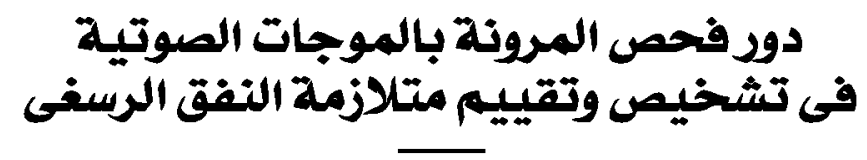

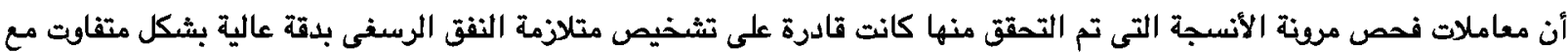

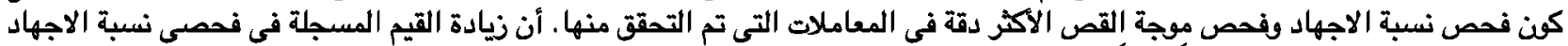

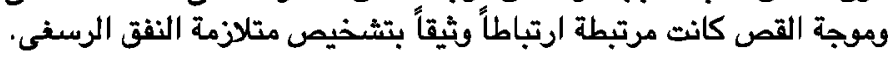

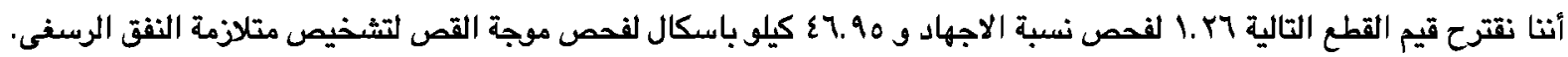

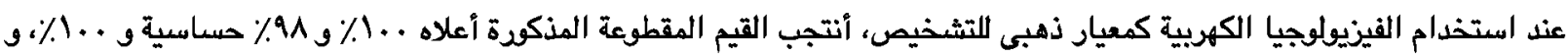

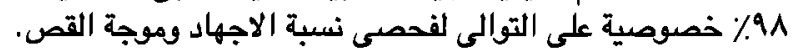

$$
\begin{aligned}
& \text { نوصى بإجراء المزيد من الدراسات مـع حجم عينة أكبر من المجموعات الفرعية للتحقيق فى قدرة فحص مرونة الأنسجة على تقييم الدرجات }
\end{aligned}
$$

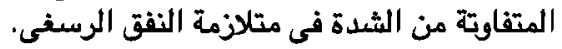

